\title{
Comment
}

\section{The role of institutional science communication}

\author{
Mauro Scanu
}

In last times scientific PR activities are increased by number and quality. Especially in United States and, more recently, in Europe all the most important research institutions and universities have been equipped with communication officers able to circulate their own information through mass media. This is undoubtedly a positive news for science. In spite of this, it's necessary to think about which effects can be created by marketing activity on scientific communication. In this commentary we asked some scientific professionals to tackle these problems from different points of view.

Ginger Pinholster presented a study on scientific communication professionals needs, co-sponsored by Max Planck Society and EurekAlert!, the science-news web service of the American Association for the Advancement of Science (AAAS). The study, titled "Myths of Science: Glowing Monkeys, Wonder Dogs, and More", was released on $16^{\text {th }}$ of August during the Euroscience Open Forum 2006 meeting in Munich (Germany). Results clearly point out that scientific journalists and research institutions press officers are increasingly eager for rapid access to researchers capable of making science more understandable to lay audiences as well as good-quality images.

To contrast the excessive power of Northern American scientific communication, Peter Green invites all European professionals to do their best to create a tool for promoting research produced in the Old Continent. At the end of 2004 a group of experts launched Communiquè, a web-portal dedicated to researchers and scientific journalists: the project should be a concrete idea to help Europe to become a knowledge based economy.

Holger Wormer wonders if scientific information can be sold as a soap box and warns about risks of a journalism under attack of marketing needs. PR activities are becoming more and more aggressive and promotional techniques are very effective and subtle. To cope with this phenomenon Wormer suggests a coalition between journalists interested in "good journalistic practice" and scientists (and their press officers) still interested in "good (and not only economically oriented) scientific practice".

Neil Calder outlines some successful institutional strategies in communicating high energy physics. The challenge is to overcome the traditional model in which every laboratory communicates without any relationship with the rest of the scientific community: at the end of 2001 heads of communications of major research institutions in physics decided to found Interactions Collaboration, to amplify the effectiveness of particle physics by pooling resources, experience and good practice. Today Interactions website is very popular, with nearly 100,000 unique visits each month. 